\title{
Síntese de Alcalóides Quinolínicos, Potenciais Fármacos para Doenças Tropicais
}

\section{Patrícia T. Baraldi, Patricia D. Duarte \& Arlene G. Corrêa}

As doenças tropicais são causadas por infecções de protozoários, levando ao sofrimento de centenas de milhões de pessoas. O tratamento para algumas das doenças tropicais ainda é limitado. Encontram-se na literatura trabalhos descritos tanto com produtos naturais quanto com compostos sintéticos que poderiam ser promissores agentes terapêuticos para essas doenças. Entre os diversos compostos, uma seleta classe de produtos naturais é a dos alcalóides e um grupo que possui atividades biológicas interessantes e amplas são os derivados quinolínicos, que podem ser encontrados em diferentes fontes microbianas e animais. Nesta revisão, serão apresentados os métodos sintéticos mais empregados para a obtenção de compostos da classe das quinolinas e quinolinonas.

Palavras-chave: alcalóides, doenças tropicais, quinolinas, quinolinonas.

Tropical diseases are caused by protozoa infections, leading to the suffering of hundreds of millions of people. Treatment for some tropical diseases is still limited. Substantial number of works in the literature describes natural products or synthetic compounds that could be promising therapeutic agents for these diseases. Among the various compounds, a select class of natural products is the alkaloids and a group that has extensive and interesting biological activities is derived from quinoline, which can be found in different microbial sources and animals. This review will explain the most widely used synthetic methods for obtaining the class of compounds quinolines and quinolinones.

Keywords: alkaloids, tropical diseases, quinolines, quinolinones. 


\section{Introdução}

Abusca por medicamentos para diversas enfermidades tem sido descrita desde as civilizações antigas. Uma fonte amplamente explorada são as plantas e o seu uso terapêutico tem sido utilizado até os dias atuais.

Apesar disto, somente a partir do século XIX houve um interesse em determinar quais eram os compostos ativos das plantas medicinais. O marco desta busca foi a descoberta da quinina (1) (Figura 1), um alcalóide obtido de cascas de Cinchona, planta encontrada na Bolívia, que na medicina popular era utilizada no tratamento de malária e cuja atividade foi atribuída a esse composto ${ }^{1}$. Outros compostos naturais com atividade antibiótica foram isolados de espécies de Penicillium, Cephalosporium e Streptomyces. A vinblastina e a vincristina, isoladas de Catharanthus roseus, têm uso efetivo na quimioterapia de câncer.

Como alguns produtos naturais bioativos possuem estruturas complexas, incluindo vários centros estereogênicos, simplificações estruturais podem ser feitas. Por exemplo, baseando-se na quinina (1) chegouse à cloroquina (nivaquina) (2), que até hoje é um medicamento utilizado para prevenção da malária em regiões de baixo risco $^{2,3}$.

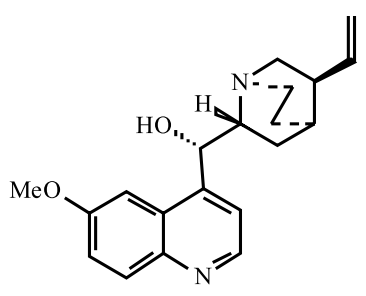

1

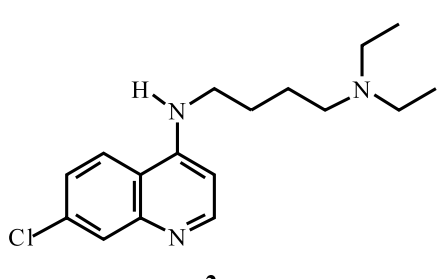

2
Figura 1. Estruturas da quinina (1) e cloroquina (2)

Tal como a malária, a leishmaniose e a tripanossomíase (Doença de Chagas) são doenças causadas por infecções de protozoários sendo muito comuns em países subtropicais ou tropicais, causando o sofrimento de centenas de milhões de pessoas. No entanto, os medicamentos disponíveis para o tratamento destas doenças são extremamente limitados ${ }^{4}$. Os fármacos disponíveis estão sendo utilizados desde o início do século passado e sua administração deve ser feita por pessoas autorizadas. Além disso, muitos parasitas desenvolveram vários graus de resistência e, como no caso da malária, tem se estendido a quase todos os fármacos agravando o problema da saúde pública.
A busca por novos tratamentos para essas doenças continua sendo realizada embora o sucesso não seja tão promissor uma vez que, de acordo com Pecoul et al. ${ }^{5}$, de 1233 novos fármacos identificados para chegar ao mercado entre 1975 e 1997, somente 13 foram aprovados para doenças tropicais. O que tem sido algumas vezes usado são entidades químicas adicionais ou combinações de fármacos. Além disso, há dificuldade ao acesso desses fármacos em países pobres.

\section{MALÁRIA}

A malária é a mais disseminada de todas as doenças infecciosas, levando o indivíduo parasitado a uma anemia intensa e, em alguns casos, com desfecho fatal. Atualmente, $40 \%$ da população mundial, principalmente nos países mais pobres, vivem sob o risco de contrair malária. A malária foi erradicada no século XX em vários países de clima temperado. Entretanto, ainda é encontrada em regiões tropicais e subtropicais do mundo, causando mais de 300 milhões de casos graves e pelo menos um milhão de mortes por ano. A maioria das mortes causadas por malária ocorre em crianças da África. O Brasil está entre os maiores focos de malária no mundo.

Os agentes etiológicos da malária humana são protozoários do gênero Plasmodium, compreendendo quatro espécies: $P$. falciparum, $P$. vivax, $P$. ovale e $P$. malariae. Os vetores são mosquitos do gênero Anopheles ${ }^{2,3,6}$. O tratamento da malária pode ser realizado com diversos medicamentos ou combinações, tais como: mefloquina (3), halofantrina (4), arteméter (5), artemeterlumefantrine (6), clorproguanil-dapsona (7 e 8), artemotil (9), DEC + albendazol (10), eflornitina (11) e ivermectina (12) + albendazol (10) (Figura 2) ${ }^{6}$.

\section{LEISHMANIOSE}

A leishmaniose é encontrada em 22 países do Novo Mundo e em 66 nações do Velho Mundo, sendo 16 na Europa, incluindo França, Itália, Grécia, Malta, Espanha e Portugal. A leishmaniose presente em humanos possui duas formas com ampla faixa de manifestações clínicas. As formas cutâneas da leishmaniose são as mais comuns e as lesões são localizadas na pele como úlceras levando a traumas permanentes. A infecção mais ampla do parasita causa outra forma da doença, a leishmaniose visceral que é caracterizada por turnos irregulares de febre, 
perda de peso significativa, inchaço do baço e fígado e anemia, sendo a forma mais severa da doença que, sem tratamento, tem uma taxa de mortalidade de quase $100 \%$. Os agentes etiológicos da leishmaniose são protozoários do gênero Leishmania e chegam a mais de 20 espécies e sub-espécies sendo que as encontradas no Brasil são: $L$. amazonensis, $L$. guyanensis, $L$. braziliensis e $L$. chagasi $^{6}$. A forma de tratamento pode ser por meio de medicamentos a base de antimônio pentavalente, sendo comercializados o pentostam (13) (estibogluconato de sódio) e a glucantime (14) (antimoniato $N$-metil glucamina), no entanto estes apresentam diversos efeitos colaterais (Figura 3) 2,3,6.
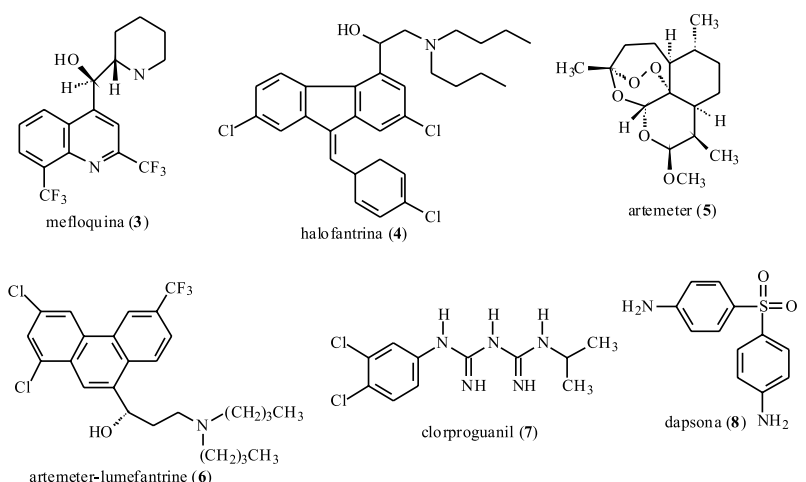

artemeter-lumefantrine $(6)$
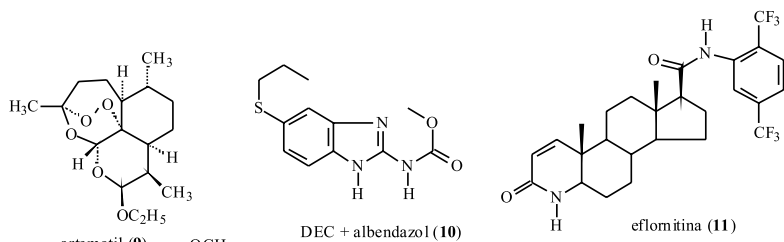<smiles>C[C@@H]1OCC[C@@H](Cl)[C@H]1O</smiles>

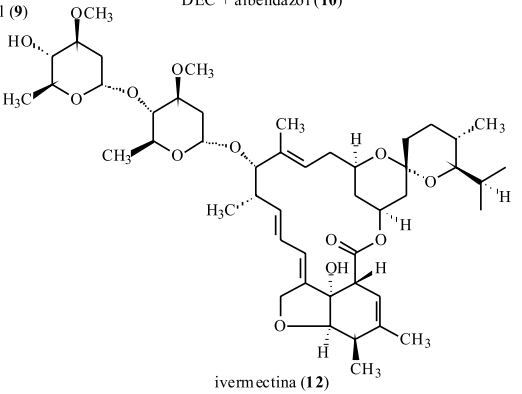

Figura 2. Fármacos empregados no tratamento da malária ${ }^{6}$

Outros fármacos disponíveis mais recentemente são, por exemplo, a pentamidina (15), anfotericina B (16), ergosterol (17) e miltefosina (18), sendo este último utilizado no tratamento de leishmaniose Kala-Azar (Figura 4) ${ }^{7}$.

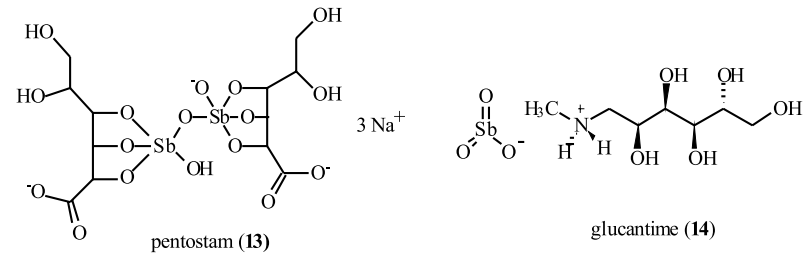

Figura 3. Fármacos empregados no tratamento da leishmaniose<smiles>N=C(N)c1ccc(OCCOc2ccc(C(=N)N)cc2)cc1</smiles>

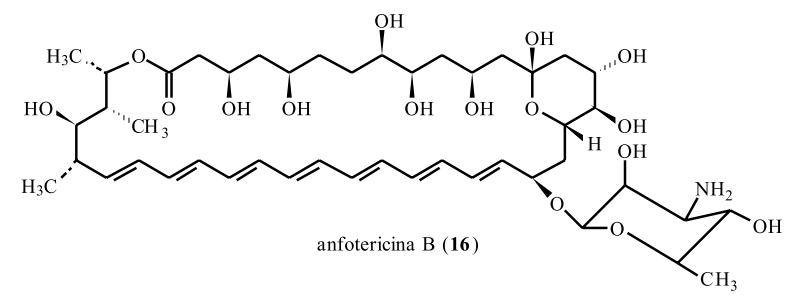<smiles>CCCCCCCCCCCCCCCCOC(=O)OCC[N+](C)(C)C</smiles>

Figura 4. Fármacos empregados no tratamento da leishmaniose

\section{DOENÇA DE CHAGAS}

A Doença de Chagas é encontrada somente na América Latina e foi descoberta por um médico brasileiro, Carlos Chagas, em 1909. A ocorrência da doença se estende desde o México até a América Central e do Sul. A migração de populações tem levado a doença para países desenvolvidos devido à transmissão por transfusão de sangue. A infecção causada por Trypanossoma cruzi é estimada ser de 16 - 18 milhões de casos por ano. Aproximadamente 120 milhões de pessoas, cerca de 25\% dos habitantes da América Latina, correm o risco de contrair a doença. Os sintomas da doença são insuficiência cardíaca, gastrintestinal ou danos neurológicos. A doença do sono, encontrada na África, é similar à de Chagas e é transmitida por T. brucei ${ }^{6}$.

Os medicamentos nifurtimox (19), benzonidazol (20) e megazol (21) (Figura 5) são capazes de curar pelo menos 
$50 \%$ de infecções recentes. Estes compostos são ativos apenas na fase aguda da doença e em curto prazo, além de apresentarem efeitos colaterais sérios e freqüentes, tendo o seu uso limitado. O que dificulta o tratamento é a indisponibilidade desses fármacos aos pacientes em países endêmicos e seu alto custo ${ }^{6}$. No Brasil, o medicamento nifurtimox não é mais comercializado devido à sua baixa eficiência e fortes efeitos colaterais como aneroxia, distúrbios gastrintestinais, neuropatias e erupções cutâneas. Além disso, o seu uso prolongado causa resistência do parasita ${ }^{8}$.
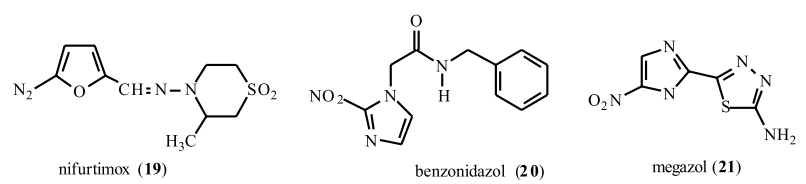

Figura 5. Medicamentos empregados no tratamento da doença de Chagas.

O tratamento para algumas das doenças tropicais ainda é limitado. Encontram-se na literatura trabalhos descritos tanto com produtos naturais quanto com compostos sintéticos que poderiam ser promissores agentes terapêuticos para essas doenças $^{8-10}$. Entre os diversos compostos, uma seleta classe de produtos naturais é a dos alcalóides ${ }^{11}$ e um grupo que possui atividades biológicas interessantes e amplas são os derivados quinolínicos, que podem ser encontrados em diferentes fontes microbianas e animais ${ }^{12-14}$.

Um exemplo são as quinolinonas, e particularmente as fluorquinolinonas, que são amplamente usadas como fármacos bactericidas e micobactericidas, no tratamento de várias doenças infecciosas. A primeira quinolinona que apresentou atividade bactericida foi o ácido nalidíxico (22) que foi isolado em 1962 (Figura 6) (15 $^{15}$<smiles>CCn1cc(C(=O)O)c(=O)c2ccc(C)cc21</smiles>

Figura 6. Estrutura do ácido nalidíxico

Uma vez descoberta a atividade de 22, mais de 10 milhões de quinolinonas foram patenteadas, que juntamente com as modificações químicas sucessivas, comprovaram o espectro de atividade, a potência e a resposta parasítica. As quinolinonas são bactericidas devido à interferência nas topoisomerases II do DNA bacterial (DNA girase) e IV, que são enzimas envolvidas na replicação, recombinação e reparo do DNA. Esta inibição resulta da formação de um forte complexo ternário entre a quinolinona e a dupla DNA/DNA girase, que capta a enzima no DNA. Há indícios de que as quinolinonas agem similarmente em alvos localizados como o apicoplasto dos parasitas T. gondii e P. falciparum e através de caminhos similares, embora nenhuma evidência definitiva tenha sido observada até o momento ${ }^{15}$. Esses fatos mostram claramente a necessidade de investigar e sintetizar novos compostos desta classe.

Para se determinar a atividade de um composto frente aos parasitas dos gêneros Leishmania, Trypanossoma e Plasmodium, inicialmente são realizados ensaios com as formas promastigotas e amastigotas in vivo e in vitro destes protozoários.

Uma abordagem moderna e alternativa na busca de fármacos e vacinas para várias doenças, inclusive as tropicais, surgiu da possibilidade de se determinar a atividade de um composto em uma determinada enzima, e isto tem sido possível devido ao avanço do sequenciamento genômico ${ }^{16}$.

Assim, a identificação de alvos potenciais apropriados é essencial para o desenvolvimento de um fármaco efetivo, sendo que a maioria dos alvos terapêuticos são tanto os receptores da parede da célula quanto as enzimas ${ }^{17}$.

Deste modo, seria oportuno identificar um caminho biossintético fundamental no parasita e bloqueá-lo através da inibição de enzimas, desde que essas não sejam essenciais ou não estejam presentes no hospedeiro. Assim, o inibidor enzimático seria convertido em um pró-fármaco no interior do parasita. Várias enzimas com diferentes funções têm sido isoladas e o estudo para se encontrar inibidores está sendo realizado ${ }^{18-21}$, no entanto encontram-se na literatura apenas estudos preliminares que relatam o uso de alcalóides e seus derivados. A busca por inibidores pode ser realizada através de ensaios biológicos em larga escala (high-throughput screening, HTS), ensaios virtuais, e a descoberta de estruturas baseadas em protótipos.

Nesta revisão, serão apresentados os métodos sintéticos mais empregados para a obtenção de compostos da classe das quinolinas e quinolinonas. 


\section{Metodologias Sintéticas}

Uma classe interessante de compostos é a das 8-quinolinaminas devido à sua versátil atividade biológica e farmacológica, tais como antimalarial e antileishmanial. A síntese da primaquina (26a) e derivados (26b-f) baseiase na alquilação direta do anel das nitroanilinas (23a-d), via uma descarboxilação oxidativa catalisada por prata que fornece os compostos (24a-f) com bons rendimentos. A reação é altamente específica na alquilação da posição C-2 do anel quinolina. Os compostos (24a-f) foram convertidos nas $N^{8}$-(4-amino-1-metilbutil)-2-alquil-6metoxi-8-quinolinaminas (25a-f) a partir da redução do grupo nitro a amino, com posterior acoplamento na cadeia lateral para fornecer os derivados (26a-f) (Esquema 1) $)^{22,23}$.

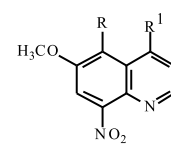

23a $R=R_{1}=H$

23b $\mathrm{R}=3$-trifluormetilfenoxi, $\mathrm{R}_{1}=\mathrm{H}$ 23c R = 3- trifluormetilfenoxi, $\mathrm{R}_{1}=\mathrm{CH}_{3}$ 23d R = 3-trifluormetilfenoxi, $\mathrm{R}_{1}=\mathrm{C}_{2} \mathrm{H}_{5}$

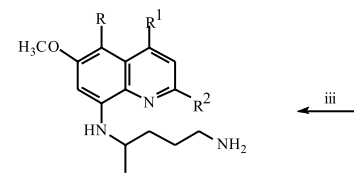

26a $\mathrm{R}=\mathrm{R}_{1}=\mathrm{R}_{2}=\mathrm{H}$

26b R $=\mathrm{R}_{1}=\mathrm{H}, \mathrm{R}_{2}=\mathrm{C}\left(\mathrm{CH}_{3}\right)_{3}$

$26 \mathrm{c} R=\mathrm{R}_{1}=\mathrm{H}, \mathrm{R}_{2}=1$-adamantil

26d R = 3-trifluormetilfenoxi, $\mathrm{R}_{1}=\mathrm{H}, \mathrm{R}_{2}=\mathrm{C}\left(\mathrm{CH}_{3}\right)_{3}$

26e $\mathrm{R}=3$-triftuormetilfenoxi, $\mathrm{R}_{1}=\mathrm{CH}_{3}, \mathrm{R}_{2}=\mathrm{C}\left(\mathrm{CH}_{3}\right)_{3}$

26f $\mathrm{R}=3$-trifluormetilfenoxi, $\mathrm{R}_{1}=\mathrm{C}_{2} \mathrm{H}_{5}, \mathrm{R}_{2}=\mathrm{C}\left(\mathrm{CH}_{3}\right)_{3}$

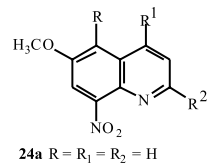

24b $R=R_{1}=H, R_{2}=C\left(\mathrm{CH}_{3}\right)_{3}$

$24 \mathrm{~b} R=\mathrm{R}_{1}=\mathrm{H}, \mathrm{R}_{2}=\left(\mathrm{CH}_{3}\right)_{3}$
$2 \mathrm{c} \mathrm{R}=\mathrm{R}_{1}=\mathrm{H}, \mathrm{R}_{2}=1$ - adamantil

24d R = 3-trifluormetilfenoxi, $\mathrm{R}_{1}=\mathrm{H}, \mathrm{R}_{2}=\mathrm{C}\left(\mathrm{CH}_{3}\right)_{3}$

24e $\mathrm{R}=$ 3-trifluormetilfenoxi, $\mathrm{R}_{1}=\mathrm{CH}_{3}, \mathrm{R}_{2}=\mathrm{C}\left(\mathrm{CH}_{3}\right)_{3}$ 24f $\mathrm{R}=3$ - trifluormetilfenoxi, $\mathrm{R}_{1}=\mathrm{C}_{2} \mathrm{H}_{5}, \mathrm{R}_{2}=\mathrm{C}\left(\mathrm{CH}_{3}\right)_{3}$

ii

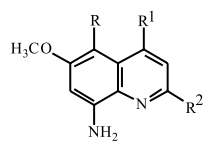

$25 \mathrm{a} R=\mathrm{R}_{1}=\mathrm{R}_{2}=\mathrm{H}$

$25 \mathrm{~b} R=\mathrm{R}_{1}=\mathrm{H}, \mathrm{R}_{2}=\mathrm{C}\left(\mathrm{CH}_{3}\right)_{3}$

$25 \mathrm{c} R=\mathrm{R}_{1}=\mathrm{H}, \mathrm{R}_{2}=1$ - adamantil

$25 \mathrm{~d} \mathrm{R}=3$-trifluormetilfenoxi, $\mathrm{R}_{1}=\mathrm{H}, \mathrm{R} \quad 2=\mathrm{C}_{2}\left(\mathrm{CH}_{3}\right)_{3}$ 25e R =3-trifluormetilfenoxi, $\mathrm{R}_{1}=\mathrm{CH}_{3}, \mathrm{R} \quad{ }_{2}=\mathrm{C}\left(\mathrm{CH}_{3}\right)_{3}$ 25f R = 3-trifluormetilfenoxi, $\mathrm{R}_{1}=\mathrm{C}_{2} \mathrm{H}_{5}, \mathrm{R}_{2}=\mathrm{C}\left(\mathrm{CH}_{3}\right)_{3}$
Condiçôes reacionais: (i) $\mathrm{RCO}_{2} \mathrm{H}, \mathrm{AgNO}_{3},\left(\mathrm{NH}_{4}\right)_{2} \mathrm{~S}_{2} \mathrm{O}_{8}, \mathrm{H}_{2} \mathrm{SO}_{4} 10 \%, \mathrm{CH}_{3} \mathrm{CN}, 70^{\circ} \mathrm{C}, 60-70 \%$; (ii) Raney Ni, $\mathrm{EtOH}, \mathrm{H}_{2}, 45 \mathrm{psi}, 45 \mathrm{~min}, 86-94 \%$; (iii) a. 2-(4-bromopentil) -1,3-isoindolindiona, $\mathrm{Et} 3 \mathrm{~N}, 120^{\circ} \mathrm{C}, 24 \mathrm{~h}, 56-83 \%$; b. $\mathrm{NH}_{2} \mathrm{NH}_{2} \cdot \mathrm{H}_{2} \mathrm{O}$, EtOH, refluxo, $8 \mathrm{~h}, 88-90 \%$.

Esquema 1. Síntese da primaquina (26a) e derivados (26b-f) ${ }^{22,23}$

Trabalhos mais recentes empregam a metodologia descrita por Price e Roberts, que envolve a condensação de uma anilina com o éster etoximetilenomalônico. Madrid e colaboradores ${ }^{24}$ modificaram este método usando o ácido metoximetileno de Meldrum, diminuindo a rota sintética em duas etapas. Algumas desvantagens encontradas são: a instabilidade do ácido de Meldrum a altas temperaturas e o uso de anilinas $m$-substituídas que geram produtos regioisoméricos.

A primeira etapa na seqüência reacional é a condensação da anilina substituída (27) com o ácido de Meldrum e trimetilortoformato em refluxo para formar o ácido metoximetileno de Meldrum in situ que, através de uma reação de adição-eliminação com a unidade metoximetileno, gera o precursor enamina (28). A posterior ciclização térmica com éter fenílico empregando micro-ondas por $5 \mathrm{~min}$ a $300^{\circ} \mathrm{C}$ levou a $\mathbf{2 9}$, que foi dissolvido em $\mathrm{POCl}_{3}$ e mantido em refluxo por $3 \mathrm{~h}$ resultando na 4-cloroquinolina (30) que, através de uma substituição nucleofílica com 3-dietilaminopropilamina, produziu 31. Os produtos finais foram obtidos com rendimentos de $70-90 \%$ (Esquema 2) ${ }^{24,25}$.

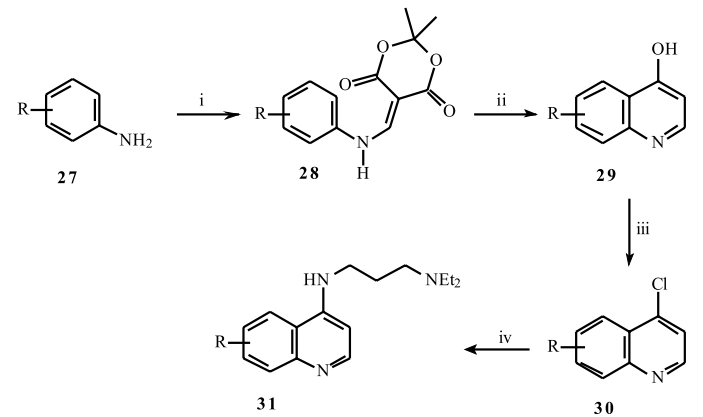

Condições reacionais: (i) Ácido de Meldrum, $\mathrm{CH}\left(\mathrm{OCH}_{3}\right)_{3}$, refluxo, $1 \mathrm{~h} .27 \mathrm{em} \mathrm{DMF}$, refluxo, $2 \mathrm{~h}$; (ii) éter fenílico, $300^{\circ} \mathrm{C}, 300 \mathrm{~W}, 5 \mathrm{~min}$; (iii) $\mathrm{POCl}_{3}$, refluxo, 3h; (iv) 3-dietilaminopropilamina, $135-155^{\circ} \mathrm{C}, 2 \mathrm{~h}$.

Esquema 2. Síntese de 4-aminoquinolinas ${ }^{24,25}$

As quinolinas do tipo 32 foram preparadas utilizandose a metodologia clássica de Sandmeyer com isatinas seguida de uma reação de Pfitzinger catalisada por base para produzir a quinolina 33, que foi esterificada empregando o intermediário cloreto de ácido e em seguida a bromação com $N$-bromosuccinimida (NBS), fornecendo 34. Este foi convertido na amida correspondente $\mathbf{3 5}$ e a posterior oxidação de Hass-Bender, utilizando o ânion nitropropano, gerou o aldeído 36. O epóxido 37 foi obtido através da ilida de enxofre e a abertura do epóxido pelo aquecimento com as aminas secundárias em etanol forneceu o composto 32 (Esquema 3) ${ }^{26}$.

Tois e colaboradores ${ }^{27}$ publicaram uma série de 4-quinolinonas sem substituições nas posições 2 ou 3, empregando o eficiente procedimento de LeimgruberBatcho. As enaninas $\mathbf{4 0}$ foram preparadas pelo aquecimento com o-nitroacetofenonas $\mathbf{3 9}$ em $\mathrm{DMF} /$ DMA. Em seguida, as enaminas foram ciclizadas com quantidade catalítica de Pd como catalisador, fornecendo as quinolonas 38 (Esquema 4).

A metodologia para a preparação das 
fluorquinolinonas baseia-se no acoplamento do cloreto de ácido obtido a partir de $\mathbf{4 2}$ com cloreto de tionila, que através de reação com 3-(dietilamino)acrilato de etila, na presença de $\mathrm{Et}_{3} \mathrm{~N}$, forneceu 43. Posterior transaminólise com ciclopropilamina ou 2,4-difluoroanilina e ciclização com $\mathrm{K}_{2} \mathrm{CO}_{3}$ em DMF gerou o éster 44. A fluorquinolina 41 pôde ser obtida pela substituição do cloro com a amina de interesse, seguida da hidrólise do éster com $\mathrm{HCl} 6 \mathrm{~N}$ em etanol (Esquema 5) 28,29 .

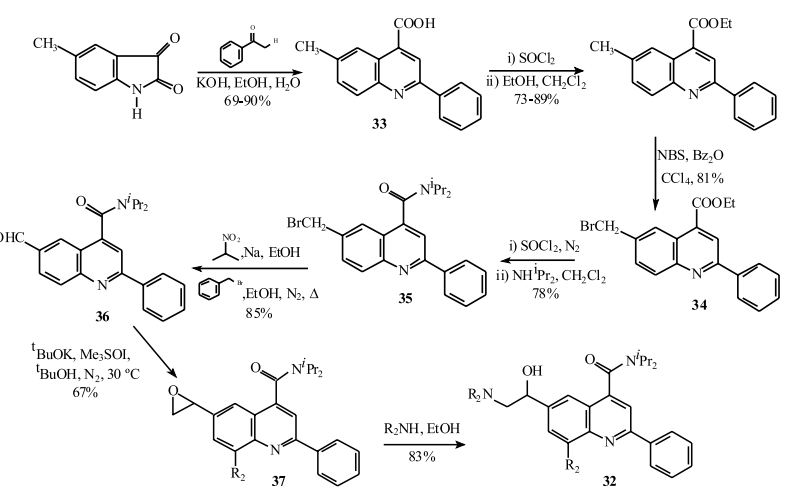

Esquema 3. Síntese de 2-aril-4-acil-quinolinas ${ }^{26}$

Além do emprego da metodologia de síntese clássica, a preparação de quinolonas também tem sido descrita empregando-se fase sólida, onde os compostos preparados encontram-se ancorados em uma resina polimérica. A vantagem seria a preparação de um maior número de compostos em um tempo menor se comparado com a síntese clássica. As indústrias farmacêuticas têm um grande interesse nesta metodologia, pois podem utilizar a química combinatória, o que traz vantagens no desenvolvimento de um fármaco.

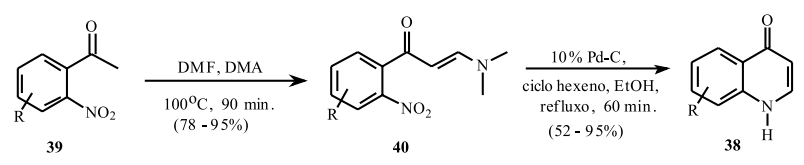

Esquema 4. Síntese de 4-quinolinonas ${ }^{27}$

Srivastava e colaboradores ${ }^{30}$ relataram a preparação das quinolinonas 45 - 48 em fase sólida a partir do acoplamento do ácido 4-aminobenzóico com a resina Merrifield (49) em meio básico para fornecer o intermediário 50. Este foi tratado com etoximetilenomalonato de dietila (DEMM) para dar a enamina 51 que foi submetida à ciclização térmica empregando Dowtherm para gerar 45. Este intermediário 45 foi submetido à modificação no grupo éster para fornecer as amidas 47. Os intermediários $\mathbf{4 5}$ e $\mathbf{4 7}$ foram clivados da resina com TFA/ $\mathrm{CH}_{2} \mathrm{Cl}_{2}$ para gerar as séries das quinolinonas $\mathbf{4 6}$ e 48 respectivamente (Esquema 6).
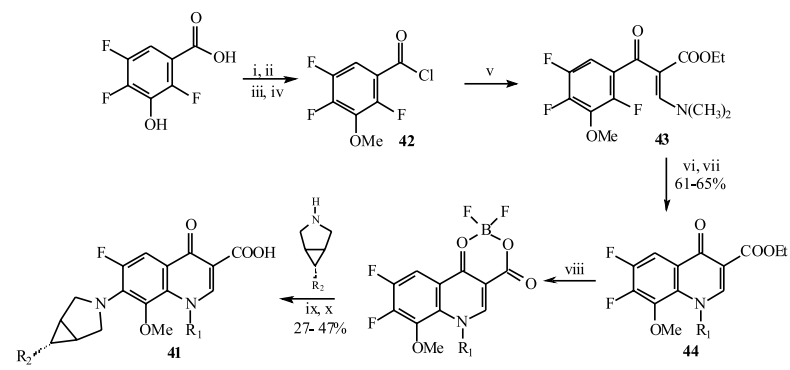

Condições reacionais: (i) MeI, DMF, $\mathrm{NaH}$, (ii) $1.0 \mathrm{~N} \mathrm{NaOH} M e O H$, (iii) $6.0 \mathrm{M} \mathrm{HCl}$, (iv) $\left(\mathrm{COCl}_{2}, \mathrm{CH}_{2} \mathrm{Cl}_{2}\right.$, cat.DMF, (v) $\left(\mathrm{CH}_{3}\right)_{2} \mathrm{NCH}=\mathrm{CHCO}_{2} \mathrm{C}_{2} \mathrm{H}_{5}, \mathrm{Et}_{3} \mathrm{~N}$, tolueno, $90^{\circ} \mathrm{C}$; (vi) $\mathrm{R}_{1} \mathrm{NH}_{2}, \mathrm{EtOH}^{\mathrm{E}} \mathrm{Et}_{2} \mathrm{O}$; (vii) $\mathrm{K}_{2} \mathrm{CO}_{3}, \mathrm{DMF}, 160^{\circ} \mathrm{C}$; (viii) $\mathrm{BF}_{3} . \mathrm{Et}_{2} \mathrm{O}$,

Esquema 5. Síntese de fluorquinolinonas ${ }^{28,29}$

Uma ferramenta que tem sido bastante utilizada para a síntese de compostos orgânicos, de um modo geral, é o uso da irradiação de micro-ondas. A radiação micro-ondas revelou-se uma fonte alternativa de aquecimento altamente eficaz em reações químicas, podendo acelerar a velocidade, proporcionar melhores rendimentos e dar origem a uma maior reprodutibilidade das reações, bem como auxiliar no desenvolvimento de novas ferramentas limpas e verdes ${ }^{31}$.

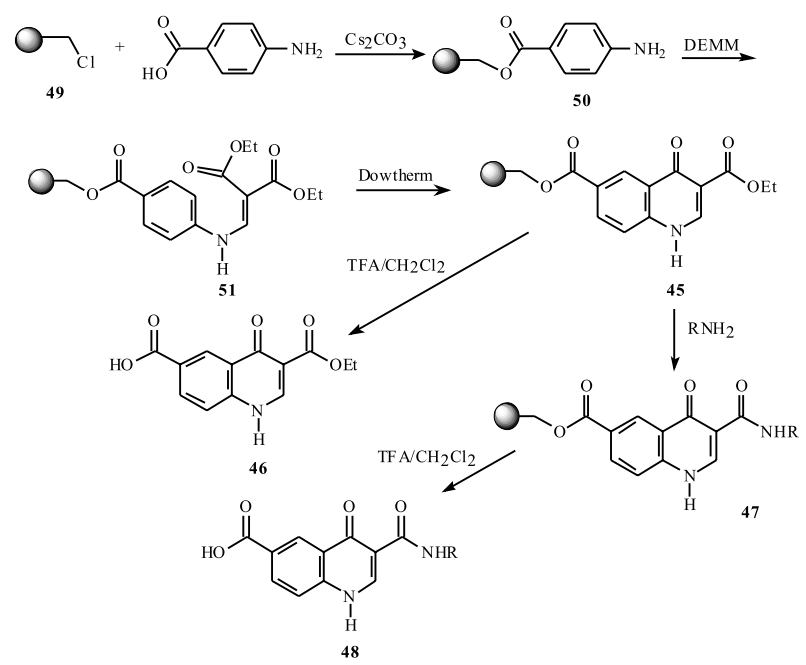

Esquema 6. Síntese em fase sólida de quinolinonas ${ }^{30}$

O emprego de micro-ondas em reações orgânicas representa um benefício considerável do ponto de vista 
energético, uma vez que as reações são, de forma geral, muito mais rápidas quando comparadas àquelas efetuadas em aquecimento convencional ${ }^{32}$. Sendo assim, muitas metodologias visando a síntese de alcalóides utilizam a irradiação de micro-ondas como fonte de energia na obtenção dos produtos.

Como exemplo, dentro deste contexto, Ding e colaboradores $^{33}$ descreveram a síntese de 2-aril-4quinolinonas 50a-p a partir de $2^{\prime}$-aminoacetofenonas aciladas 49a-p, sob irradiação de micro-ondas. As 2'-aminoacetofenonas aciladas foram submetidas à irradiação de micro-ondas na presença de $\mathrm{NaOH}$, utilizando $t-\mathrm{BuOH}$ como solvente, à $120^{\circ} \mathrm{C}$, durante um período de 10 minutos (Esquema 7).
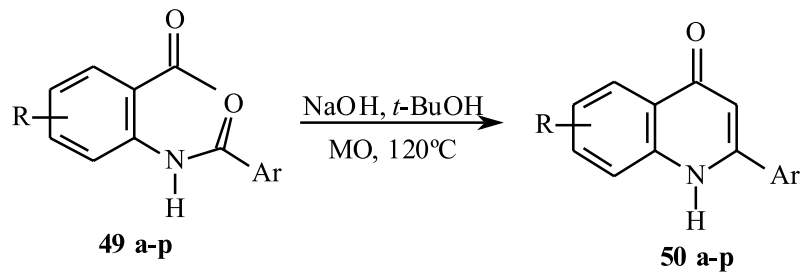

Esquema 7. Síntese de derivados de 4-quinolinonas sob irradiação de micro-ondas ${ }^{33}$

Os derivados de 2-aril-4-quinolinonas foram obtidos em bons rendimentos, que variaram de 57 a 95\%, com significativa diminuição do tempo reacional, quando comparado ao aquecimento convencional (10-24 h).

Outro exemplo foi reportado por Albrecht e colaboradores $^{34}$, que apresentaram um procedimento fácil através do uso da irradiação de micro-ondas para a preparação de quinolinonas funcionalizadas na posição 2 ou 3. Os compostos preparados podem facilmente ser modificados para a obtenção das respectivas 4-cloroquinolinas (Esquema 8).

A síntese de derivados de quinolinas foi descrita por Kidwai e colaboradores ${ }^{35}$ utilizando a irradiação de micro-ondas, porém sem a utilização de solvente para a realização da reação. Os químicos orgânicos estão cada vez mais empenhados em desenvolver metodologias sintéticas verdes e o não uso de solventes em reações e a utilização do aquecimento por micro-ondas são fundamentais dentro deste contexto ${ }^{36}$.

Neste artigo, os autores descrevem a síntese das quinolinas 62a-h, através da reação entre derivados de anilinas 60a-h e acetoacetato de etila (61), utilizando temperatura entre $80-100^{\circ} \mathrm{C}$, em um curto intervalo de tempo, que variou entre 25 a 100 segundos, dando origem aos produtos desejados em excelentes rendimentos (Esquema 9).

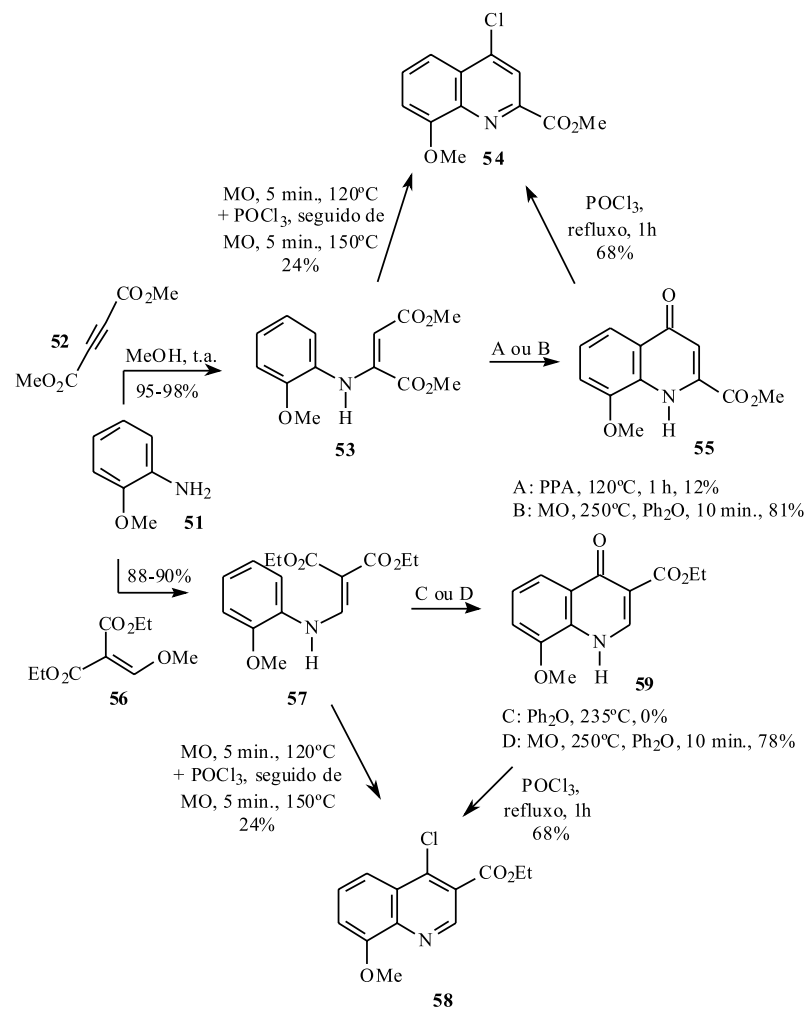

Esquema 8. Síntese de quinolinonas e quinolinas ${ }^{34}$

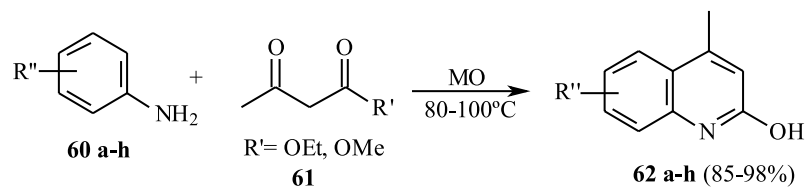

Esquema 9. Síntese de quinolinas sob irradiação de micro-ondas sem solvente $^{35}$

\section{Conclusões}

Procurou-se nesta revisão colaborar com os estudos na busca por novos fármacos para doenças tropicais, descrevendo a síntese de compostos da classe dos alcalóides quinolínicos com potencial atividade antiparasitária. Como se pode observar pela diversidade de métodos apresentados, uma ampla gama de derivados 
quinolínicos podem ser preparados em poucas etapas sintéticas, fornecendo rapidamente um número grande de compostos para serem avaliados frente a sua atividade biológica.

\section{Agradecimentos}

As autoras agradem o apoio financeiro da FAPESP, CAPES e CNPq.

\section{Referências}

1. Phillipson, J. D.; Phytochemistry 2001, 56, 237.

2. Silva, T. H. A.; Oliveira, M. T.; Santos, H. F.; Oliveira, A. B.; Almeida, W. B.; Quim. Nova 2005, 28, 244.

3. Silva, J. B. Jr. Guia de Vigilância Epidemiológica, $4^{\mathrm{a}}$ ed., Ministério da Saúde - Fundação Nacional da Saúde: Brasil, 1998, cap. 5.16.

4. Cavalli, A., Bolognesi, M. L.; J. Med. Chem. 2009, 52, 7339.

5. Pecoul, B.; Chirac, P.; Trouiller, P.; Pinel, J.; J. Am. Med. Ass. 1999, 281, 361.

6. http://apps.who.int/tdr/, acessada em outubro de 2011.

7. Ouellette, M.; Drummelsmith, J.; Papadopoulou, B.; Drug Resist. Update 2004, 7, 257.

8. Elias, B. C.; Dissertação de Mestrado, Universidade de São Paulo, Ribeirão Preto, Brasil, 2003.

9. Akendengue, B.; Ngou-Milama, E.; Laurens, A.; Hocquemiller, R.; Parasite 1999, 6, 3.

10. Hamzah, J.; Skinner-Adams, T.; Davis, T. M. E.; Acta Tropica 2000, 74, 39.

11. Cordell, G. A.; Quinn-Beattie, M. L.; Farnsworth, N. R.; Phytother. Res. 2001, 15, 183.

12. Lescher, G. Y.; Froelich, E. J.; Gruett, M. D.; Bailey, J. H.; Brundage, R. P.; J. Med. Pharm. Chem. 1962, 5, 1063.

13. Michael, J. P.; Nat. Prod. Rep. 2004, 21, 650.

14. Michael, J. P.; Nat. Prod. Rep. 2005, 22, 627.

15. Anquetin, G.; Greiner, J.; Vierling, P.; Tetrahedron 2005, 61, 8394.

16. Carucci, D. J.; Vaccine 2001, 19, 2315.

17. Davis, A. J.; Murray, H. W.; Handman, E.; Trends Parasit. 2004, 20, 73.

18. Urbina, J. A.; Concepcion, J. L.; Rangel, S.; Visbal, G.; Lira, R.; Mol. Biochem. Parasit. 2002, 125, 35.

19. Ladame, S.; Castilho, M. S.; Silva, C. H. T. P.; Denier, C.; Hannaert, V.; Périe, J.; Oliva, G.; Willson, M.; Eur. J. Biochem. 2003, 270, 4574.
20. Alvim, Jr, J.; Dias, R. L. A.; Castilho, M. S.; Oliva, G.; Correa, A. G.; J. Braz. Chem. Soc. 2005, 16, 763.

21. Leitão, A.; Andricopulo, A. D.; Oliva, G.; Pupo, M. T.; Marchi, A. A.; Vieira, P.C.; Silva, M. F. G. F.; Ferreira, V. F.; Souza, M. C. B. V.; Sá, M. M.; Moraes, V. R. S.; Montanari, C. A.; Bioorg. Med. Chem. 2004, 14, 2199.

22. Jain, M.; Khan, S. I.; Tekwani, B. L.; Jacob, M. R.; Singh, S.; Singh, P. P.; Jain, R.; Bioorg. Med. Chem. 2005, 13, 4458.

23. Jain, M.; Vangapandu, S.; Sachdeva, S.; Singh, S.; Singh, P. P.; Jena, G. B.; Tikoo, K.; Ramarao, P.; Kaul, C. L.; Jain, R.; J. Med. Chem. 2004, 47, 285.

24. Madrid, P. B.; Sherrill, J.; Liou, A. P.; Weisman, J. L.; DeRisi, J. L.; Guy, R. K.; Bioorg. Med. Chem. Lett. 2005, 15, 1015.

25. Madrid, P. B.; Wilson, N. T.; DeRisi, J. L.; Guy, R. K.; J. Comb. Chem. 2004, 6, 437.

26. Boa, A. N.; Canavan, S. P.; Hirst, P. R.; Ramsey, C.; Stead, A. M. W.; McConkey, G. A.; Bioorg. Med. Chem. 2005, 13, 1945.

27. Tois, J.; Vahermo, M.; Koskinen, A.; Tetrahedron Lett. 2005, 46, 735.

28. Anquetin, G.; Rouquayrol, M.; Mahmoudi, N.; Santilla-Hayat, M.; Gozalbes, R.; Greiner, J.; Farhati, K.; Derouin, F.; Guedj, R.; Vierling, P.; Bioorg. Med. Chem. Lett. 2004, 14, 2773.

29. Cecchetti, V.; Tabarrini, O.; Sabatini, S.; Miao, H.; Filipponi, E.; Fravolini, A.; Bioorg. Med. Chem 1999, 7, 2465.

30. Srivastava, S. K.; Haq, W.; Murthy, P. K.; Chauhan, P. M. S.; Bioorg. Med. Chem. Lett. 1999, 9, 1885.

31. Kappe, C. O. Angew. Chem. Int. Ed. 2004, 43, 6250.

32. Corrêa, A. G.; Zuin, V. G.; Química Verde: Fundamentos e Aplicações - São Carlos: EdUFSCar, 2009.

33. Ding, D.; Li, X.; Wang, X.; Du, Y.; Shen, J.; Tetrahedron Lett. 2006, 47, 6997.

34. Albrecht, M.; Osetska, O.; Rantanen, T.; Fröhlich, R.; Bolma, C.; Synlett 2010, 1081.

35. Kidwa, M.; Bansal, V.; Lett. Org. Chem., 2007, 4, 519.

36. Kidwai, M.; Venkataramana, R.; Dave, B. Green Chem. 2001, 3, 278.

\section{Patrícia T. Baraldi ${ }^{1,2}$, Patricia D. Duarte $^{1}$ \& Arlene G. Corrêa ${ }^{1 *}$}

${ }^{1}$ Departamento de Química, Universidade Federal de São Carlos, Rodovia Washington Luiz, km 235, CP 676, CEP 13.565-905 - São Carlos/SP.

${ }^{2}$ Instituto Vita Nova, Rua Barão de Itapura 135, CEP 13.186-481 -Hortolandia/SP

*e-mail: agcorrea@ufscar.br 